\title{
Design and Performance Analysis of a Novel
}

\section{Synchronous Reluctance Machine}

\author{
Shaopeng Wang ${ }^{1,2}$ Jinguang Ma ${ }^{1,2}$ Chengcheng Liu ${ }^{1,2, *}$ Youhua Wang ${ }^{1,2}$ Gang Lei $^{3}$ \\ Youguang Guo ${ }^{3} \quad$ Jianguo Zhu ${ }^{4}$
}

(1. State Key Laboratory of Reliability and Intelligence of Electrical Equipment, Hebei University of Technology Tianjin 300132 China

2. Key Laboratory of Electromagnetic Field and Electrical Apparatus Reliability of Hebei Province Hebei University of Technology Tianjin 300132 China

3. School of Electrical and Data Engineering University of Technology Sydney Sydney NSW 2007 Australia

4. School of Electrical and Information Engineering University of Sydney NSW 2007 Sydney Australia)

Corresponding author: Chengcheng Liu, Hebei University of Technology, No. 8, Guangrong Road, Hongqiao District, Tianjin, 300130, China. Tel.: 13752694973; Email:2016020@ hebut.edu.cn 


\title{
Design and Performance Analysis of a Novel
}

\section{Synchronous Reluctance Machine}

\begin{abstract}
To improve output torque ability and reduce torque ripple in traditional synchronous reluctance motor (TSynRM), a new synchronous reluctance motor (NSynRM) is proposed in this paper. The rotor of NSynRM is composed of both grainoriented silicon steel and non-oriented silicon steel. With the reasonable design of rotor structure, the torque of NSynRM has been improved and its torque ripple has been reduced greatly. Firstly, TSynRM and NSynRM are qualitatively compared by using the magnetic network method. Secondly, the main parameters of these two machines are optimized by using finite element method (FEM). Then the performance comparison between two optimized machines are carried out. Finally, the equivalent stress of these two machines at the maximum speed are analyzed. It can be seen that NSynRM can have $6.8 \%$ higher torque under rated load, $8 \%$ higher torque under maximum load, $17.5 \%$ wider constant torque operation region, and lower torque ripple compared with the TSynRM.
\end{abstract}

Keywords: Synchronous reluctance machine, grain-oriented silicon steel, reluctance torque, magnetic network analysis, finite element method.

\section{Introduction}

By using high co-energy permanent magnet (PM) to produce the magnetic field, PM machine can have the benefits of high output torque ability, high efficiency and high power density, thus the PM machines have been widely used for different energy conversion appliances [1-4]. However the material cost of rare earth PM is very high, which makes the cost of PM machine is high. In addition the PM machine cannot avoid irreversible demagnetization risk. Thus synchronous reluctance machine (SynRM) without using the PM have drawn a great of attention in the past years[5-7].

The stator of SynRM is the same as that of traditional induction machine and synchronous machine, the rotor of SynRM is designed with multi-layer magnetic barrier and thus the high saliency ratio can be resulted and the 
reluctance torque can be produced. The SynRM has the advantages of simple structure, low rotor loss, good mechanical robust and low cost, it also with the disadvantages of low torque density and power factor when compared with the PM machine.

The stator structure and winding configuration of SynRM are almost fixed, and the performance improvement of this kind of machine depends on using new optimized rotor structure. In [8], a form blocked rotor structure is proposed for SynRM, the experiment results show that this new structure can improve the rotor robustness and the maximum speed of the machine has been increased without reducing its magnetic performance. In [9], a new so-called Machaon rotor structure is proposed for the SynRM, the center symmetric line of the rotor barrier for each pole is kept unchanged, however the angle for the barrier in different poles can be changed, thus the torque ripple can be reduced by optimizing this angle.

There are two different kind of silicon steels can be used for building the rotor of SynRM, one is the nonoriented silicon steel sheets and another one is the grain oriented steel sheets. The permeability of non-oriented silicon steels sheets in all directions are same. For the grain oriented silicon steel sheets, its permeability along the rolling direction is very high and its core loss along this direction is very low, while for the other directions its magnetic characteristic is quite bad. In [10], a new rotor for SynRM is proposed, each pole of rotor core are made by the grain oriented silicon steel sheet stacked with its rolling direction along the d-axis direction and the shear direction along the axial direction. The experiment results show that the saliency ratio and the torque ability of this machine is very high, however this structure is very complex and the mechanical robustness is not good. In [11], a flux switching permanent magnet machine with grain oriented steel cores is proposed, the simulation results show that its torque has been improved $20 \%$ higher than that of the traditional flux switching machine.

A new synchronous reluctance machine (NSynRM) is proposed in this paper, it is designed with the grain oriented steel sheets inserted into the part of magnetic barrier of rotor core, where the rolling direction of the grain oriented steel sheets are along the $\mathrm{d}$-axis direction and the stacking direction of that are along the q-axis direction, thus the saliency ratio of this machine has been improved. By using the finite element method (FEM), the torque, torque ripple, power factor, efficiency of NSynRM and TSynRM have been both optimized, and the performance between these two machines are compared, it shows that both the saliency ratio, torque ability, power factor, efficiency of the new machine has been improved greatly. The main design parameters of the proposed machines are shown in Table 1.

\section{Rotor structure for TSynRM and NSynRM}




\subsection{Rotor structure model}

The torque of SynRM can be expressed by,

$$
T_{e}=\frac{3}{2} P\left(L_{d}-L_{q}\right) i d_{i q}
$$

where $P$ is the number of pole pairs, $L_{d}$ the d-axis inductance, $L_{q}$ the q-axis inductance, $i_{d}$ the d-axis current , and $i_{q}$ the q-axis current. To improve the torque ability of SynRM, the saliency ratio which means that the difference between the d-axis inductance and the q-axis inductance needs to be enlarged [12-15]. When the current is applied in the SynRM, the magnetic flux will increase and the magnetic bridge will be saturated, thus the grain-oriented steel sheets are proposed to replace some part of the magnetic bridge. With proper designing the ratio of grainoriented steel sheets in rotor, the magnetic bridge saturation can be reduced and thus the difference between the d-axis inductance and q-axis inductance can be improved when the current is applied. Fig. 1 shows the rotor structure with three magnetic barrier layers, Fig. 1(a) shows the rotor for the TSynRM, Fig. 1(b) and (c) show the rotor for the NSynRM. As shown in Fig. 1(b) and (c), the main part of the rotor of NSynRM is made by the nonoriented silicon steel sheets and the grain oriented steel sheets are surface mounted on top side of the magnetic bridge, and the rolling direction of the grain oriented steel sheets is along the d-axis direction and the stacking direction of the grain oriented steel sheets is along the q-axis direction.

\subsection{D-axis magnetic circuit model}

Fig. 2 shows the magnetic flux line of the SynRM excited by the d-axis current excitation. As shown, the magnetic flux line is along the stator, air gap and rotor to form a closed loop. The magnetic potential at the different position of magnetic barrier is different, thus the magnetic flux will follow the magnetic bridge where the magnetic resistance is minimum and then the air gap and back to the stator teeth and stator yoke to form a closed loop. The d-axis magnetic circuit model and equivalent magnetic circuit model for the TSynRM and NSynRM are shown in Fig. 3, considering that the magnetic circuit is symmetrical and thus the magnetic circuit under one magnetic pole needs to be analyzed.

In Fig. $3, F_{d}$ is the magneto motive force produced by the d-axis current, $R_{e}$ the magnetic resistance for the stator yoke, $R_{c}$ the magnetic resistance for the stator teeth, $R_{a}$ the magnetic resistance for the air gap, $R_{r}$ the magnetic resistance for the magnetic bridge, and $R_{t}$ the magnetic resistance for the grain oriented silicon steel along the rolling direction. $\varphi_{1}, \varphi_{2}, \varphi_{3}, \varphi_{N 1}, \varphi_{N 2}, \varphi_{N 3}$ are the magnetic flux through the different magnetic bridge in two 
machine, as shown in Fig. 3, and they can be expressed by,

$$
\begin{aligned}
& \Phi_{2}=\left(F_{d 2}-\frac{R_{4}}{R_{3}+R_{4}}\left(F_{d 3}-\frac{R_{4}}{R_{1}}\left(F_{d 1}-F_{d 2}\right)\right)-\frac{R_{4}+R_{5}}{R_{1}}\left(F_{d 1}-F_{d 2}\right)\right) /\left(R_{2}+R_{4}+R_{5}+\frac{R_{4}+R_{5}}{R_{1}} R_{2}-\frac{R_{4}{ }^{2}}{R_{3}+R_{4}}\left(\frac{R_{2}}{R_{1}}+1\right)\right) \\
& \Phi_{1}=\frac{1}{R_{3}+R_{4}}\left(F_{d 3}-\frac{R_{4}}{R_{1}}\left(F_{d 1}-F_{d 2}\right)\right)-R_{4} \frac{R_{1}++R_{2}}{R_{1}} \Phi_{2} \\
& \Phi_{3}=\frac{\left(F_{d 1}-F_{d 2}\right)+R_{2} \Phi_{2}}{R_{1}}
\end{aligned}
$$

As magnetic resistance for the stator part is much lower than that of the air gap, thus $R_{e}$, and $R_{t}$ can be regarded as 0 and above equations can be calculated by,

$$
\begin{aligned}
& \Phi_{1}=\frac{F_{d 1}}{R_{a 1}+R_{r 1}} ; \Phi_{2}=\frac{F_{d 2}}{R_{a 2}+R_{r 2}} ; \Phi_{3}=\frac{F_{d 3}}{R_{a 3}+R_{r 3}} \\
& \Phi_{N 1}=\frac{F_{d 1}}{R_{a 1}+R_{r 1}} ; \Phi_{N 2}=\frac{F_{d 2}}{R_{a 2}+R_{r 2}^{\prime} / / R_{t 2}} ; \Phi_{N 3}=\frac{F_{d 3}}{R_{a 3}+R_{r 3}^{\prime} / / R_{t 3}} ; \\
& \Phi_{d}=\Phi_{1}+\Phi_{2}+\Phi_{3} ; \Phi_{N d}=\Phi_{N 1}+\Phi_{N 2}+\Phi_{N 3} \\
& L_{d}=\frac{\Phi_{d}}{i_{d}} ; L_{N d}=\frac{\Phi_{N d}}{i d}
\end{aligned}
$$

$L_{d}, \quad L_{N d}$ is the d-axis inductance for the TSynRM and NSynRM respectively, comparing (5) and (6), it can be found that $\Phi_{1}=\Phi_{N 1}, \quad \Phi_{2}<\Phi_{N 2}, \quad \Phi_{3}<\Phi_{N 3}$, and thus $\Phi_{d}<\Phi_{N d}, \quad L_{d}<L_{N d}$. It can be seen that the d-axis inductance for the NSynRM is higher than that of the TSynRM. As the kneel point of the grain-oriented silicon steel is higher than that of the non-oriented silicon steel, the magnetic flux will across the grain oriented steel sheets first. Therefore when the magnetic bridge is saturated, the d-axis inductance in the NSynRM will not be reduced greatly as that in the TSynRM.

\subsection{Q-axis magnetic circuit model}

Fig. 4 shows the magnetic flux line of the SynRM excited by the q-axis current, it can be seen the magnetic flux line follows along the stator, air gap and rotor to form a closed loop. The magneto motive force at the two side of the magnetic barrier is the same with the q-axis current excitation, and the magnetic flux can only enter the magnetic barrier in the rotor core. As shown in Fig. 2 and Fig. 4, the d-axis magnetic flux can reach to 0.055 
$\mathrm{Wb} / \mathrm{m}$, while the q-axis magnetic flux can reach to $0.049 \mathrm{~Wb} / \mathrm{m}$.

Fig. 5 shows the q-axis magnetic circuit and q-axis equivalent magnetic circuit of the machine. As the thickness of magnetic separation bridge is very small and the magnetic flux leakage makes it to reach the saturation state, thus $F_{q 3}$ can be regarded as opened, and when the magnetic separation bridge is saturated then the magnetic flux through this part will be constant thus the magnetic flux source $\Phi_{b}$ can be used in the equivalent magnetic circuit model.

In Fig. $5, F_{q}$ is the magneto motive force produced by the q-axis current and $R_{e}, R_{c}, R_{a}$ have the same meanings as those in the d-axis magnetic circuit model, $R_{q}$ the magnetic resistance for the magnetic barrier, and $R_{s}$ the magnetic resistance of the grain oriented steel sheets along the q-axis direction. $\varphi_{q 1}, \varphi_{q 2}, \varphi_{q 3}, \varphi_{N q 1}, \varphi_{N q 2}, \varphi_{N q 3}$ are the magnetic flux across the magnetic barrier in two machines. For the q-axis magnetic circuit model, the magnetic resistance for the air magnetic barrier and grain oriented steel sheets along the stacking direction needs to be considered, and thus the $R_{e}, R_{c}$ are regarded as the shorted. The following equations can be obtained,

$$
\begin{aligned}
& \Phi_{q 1}=\frac{F_{q 1}}{R_{a 1}+R_{q 1}} ; \Phi_{s}=\frac{F_{q 2}+R_{q 2} \Phi_{b}}{R_{a 2}+R_{q 2}} \\
& \Phi_{N q 1}=\frac{F_{q 1}}{R_{a l}+R_{q 1}+R_{s l}} ; \Phi_{N s}=\frac{F_{q 2}+\left(R_{q 2}+R_{s 2}\right) \Phi_{b}}{R_{a 2}+R_{q 2}+R_{s 2}} \\
& \Phi_{q}=\Phi_{q 1}+\Phi_{s} ; \quad L_{q}=\frac{\Phi_{q}}{I_{q}} \\
& \Phi_{N q}=\Phi_{N q 1}+\Phi_{N s} ; \\
& L N q=\frac{\Phi_{N q}}{I_{q}}
\end{aligned}
$$

As the permeability of the grain oriented silicon steels along the stacking direction is very low, thus the $R_{s}$ is very high, based on (9) to (12), it can be seen that both the q-axis magnetic flux and inductance in the NSynRM are lower than those in the TSynRM.

Based on the magnetic circuit model, the difference between the TSynRM and NSynRM are compared in the qualitative way. It can be seen that with the adoption of grain oriented steel sheets, the $\Phi_{n d}$ and $L_{n d}$ are increased while the $\Phi_{n q}$ and $L_{n q}$ are decreased, thus the reluctance torque can be improved. Fig. 6 shows the magnetic flux density distribution of these two machines with the excitation current density of $20 \mathrm{~A} / \mathrm{mm}^{2}$.

Fig. 6(a) shows the magnetization curve of the non-oriented silicon steel sheets, it can be seen that the kneel 
point of this material is about $1.4 \mathrm{~T}$, and Fig. 6(b) and Fig6(c) shows the magnetization curve of the grain-oriented silicon steel sheets along the rolling direction and the stacking direction. Fig. 6(d) and Fig. 6(e) shows the magnetic flux density distribution on the rotor core. It can be seen that the magnetic flux density in the magnetic bridge in the TSynRM is saturated and the maximum flux density is about $1.75 \mathrm{~T}$. For the NSynRM, the magnetic flux density is about $1.5 \mathrm{~T}$, and the flux density on the grain oriented silicon steel sheet is very high, which is resulted by high permeability characteristic of the used material. The magnetic separation bridge are both saturated for these two machines.

\section{Parameter optimization of two SynRMs}

\subsection{Design optimization for TSynRM}

Fig. 7 shows the main parameters for design optimization in the TSynRM. The rotor of TSynRM is made by only using the non-oriented silicon steels, $S_{q i}$ is the magnetic bridge width along the q-axis, $W_{q i}$ is the magnetic barrier width along the $\mathrm{q}$-axis direction, $\alpha$ is the angle between the first magnetic barrier and $\mathrm{q}$-axis, and $\beta_{i}$ is the magnetic barrier angle, where $i$ means the layer number.

The ratio of the magnetic bridge to total rotor is defined by,

$$
K=\frac{\sum W_{q i}}{\sum\left(W_{q i}+S_{q i}\right)}
$$

As reported in [16], when $K$ equals about $0.5-0.55$, the torque can be maximized and the torque ripple can be minimized, when $K<0.5$ then the SynRM will face heavy magnetic flux leakage issue and then the torque ability will be reduced, on the other hand when $K>0.55$ then the magnetic bridge will be statured and the torque ripple will be increased. In this paper, $S_{d}=52 \mathrm{~mm}$, and when $K=0.5$, then $\sum W_{q i}=\sum W_{s i}=26 \mathrm{~mm}$. The average torque and torque ripple against the variation of flux barrier end angles when $\beta_{3}$ equals $2.5 \mathrm{deg}$, $3 \mathrm{deg}$, and $3.5 \mathrm{deg}$ are illustrated in Fig. 8. It can be seen that the average torque increases with the increases of $\beta_{1}$ and $\beta_{3}$, the average torque increases first and then reduces with the increases of $\beta_{2}$ and when it equals about $4.5 \operatorname{deg} \sim 5.5$ the torque can be maximized. For torque ripple, it can be seen that the lower $\beta_{1}$ the lower torque ripple, the higher $\beta_{3}$ the higher torque ripple, and the torque ripple can be minimized when $\beta_{2}$ equals about 5.5 deg to $6 \mathrm{deg}$. Comparing with the torque ripple, the variation of torque with the variation of flux barrier end angle is quite low. In this paper, $\beta_{1}=4$ $\mathrm{deg}, \beta_{2}=6 \mathrm{deg}, \beta_{3}=2.5 \mathrm{deg}$ is picked for the TSynRM design, and then its torque is $215 \mathrm{Nm}$, and its torque ripple is $7.2 \%$. 
Fig. 9 shows the average torque and torque ripple against the magnetic barrier width variation, as $K$ is set as 0.5 , thus when $W_{q 1}$ and $W_{q 2}$ are determined, $W_{q 3}$ will be determined as well. As shown, when $W_{q l}$ increases the torque decreases while the torque ripple decreases first then it will increases and the minimum torque ripple can be achieved. As for $W_{q 2}$, when it increases torque will increase first and then decrease and the torque ripple will decrease first and then increase. Therefore, $W_{q 1}=W_{q 2}=8 \mathrm{~mm}$ and $W_{q 3}=10 \mathrm{~mm}$ is determined for the machine design, then its torque is about $216 \mathrm{Nm}$ and its torque ripple is about 7.9\%. It can be seen that when the magnetic barrier width in the different layers are different then the good performance can be achieved[17,18].

\subsection{Design optimization for NSynRM}

For the electrical machine design, the optimization is essential and it needs to be optimized under the determined control method[19-20]. NSynRM share the same stator and winding configuration with TSynRM, the main difference are the rotor is made by using both the non oriented silicon steel and grain oriented silicon steel. In Fig. 10, the meanings of $W_{q i}, \alpha, \beta_{i}$ are the same as those shown in Fig. 7, and $S_{q i}, L_{q i}$ are the width of magnetic bridge made by non oriented silicon steel and grain oriented silicon steel respectively, where $i$ means the layer number. For NSynRM, $K$ is determined as 0.5 as well.

The average torque and torque ripple against the variation of magnetic barrier end angle are shown in Fig. 11. It can be seen that both the average torque and torque ripple increases with the increases of $\beta_{1}$, when $\beta_{2}$ equals 3.5 deg 4.5 deg the torque will be maximized and the torque ripple will be minimized, and when $\beta_{3}$ increases the variation of torque is small however the torque ripple will be increased. As shown, the variation of torque with the variation of $\beta_{i}$ is quite low, however the variation of torque ripple is very high. For the NSynRM, the $\beta_{I}=2.5$ $\operatorname{deg}, \beta_{2}=3.5 \mathrm{deg}, \beta_{3}=2.5 \mathrm{deg}$ are determined, where its corresponding torque is $231 \mathrm{Nm}$ and torque ripple is $6.6 \%$.

Fig. 12 shows the average torque and torque ripple against the variation of magnetic barrier width. As shown, with the $W_{q 1}$ and $W_{q 2}$ increases, the torque increases first and then decreases. And the torque ripple main depends on the $W_{q 2}$, and when $W_{q 2}$ equals about $6.5 \mathrm{~mm} \sim 8.5 \mathrm{~mm}$, the torque ripple can be minimized. Finally, $W_{q 1}=4.5$ $\mathrm{mm}, W_{q 2}=6.5 \mathrm{~mm}, W_{q 3}=15 \mathrm{~mm}$ are determined, then its corresponding torque is about $231.8 \mathrm{Nm}$ and torque ripple is about $6.8 \%$. It can be seen that both $W_{q l}$ and $W_{q 2}$ is quite low, as the grain oriented silicon steel sheets are existed in the first and second magnetic barrier as shown in Fig. 10.

Fig. 13 shows the torque increases and the torque ripple increases first and then decreases with the increases of $L_{q 1}$ and $L_{q 2}$, When $L_{q 1}$ equals about $1.6 \mathrm{~mm} \sim 2.0 \mathrm{~mm}$ and $L_{q 2}$ equals about $1.3 \mathrm{~mm} \sim 1.6 \mathrm{~mm}$, then the minimum torque ripple can be achieved. Finally, $L_{q 1}=1.6 \mathrm{~mm}$ and $L_{q 2}=1.3 \mathrm{~mm}$ is determined, and then the torque is about 
$232 \mathrm{Nm}$ and torque ripple is $6.9 \%$.

For the calculation of torque in above design the current density of $20 \mathrm{~A} / \mathrm{mm}^{2}$ is adopted. It can be seen that when the grain-oriented silicon steel sheet is used then the torque of NSynRM has been increased about 6.8\%, and the torque ripple has been reduced about $1 \%$. The obtained main dimension for above two machines are tabulated in Table 2.

\section{Performance comparison}

As shown in (1), high value of $L_{d}$ and low value of $L_{q}$ is required for SynRM, and saliency ratio is the key index which is defined by the $L_{d}$ divides $L_{q}$. Fig. 14 shows the calculated d-axis inductance and q-axis inductance with the variation of d-axis and q-axis current density in above two machines.

It can be seen that with the d-axis current and q-axis current increases, both the d-axis inductance and q-axis inductance decreases. Compared with q-axis current, d-axis current plays a more important role, since when it is very low the d-axis magnetic circuit will not be saturated, and with the $I_{d}$ increases the d-axis magnetic circuit will saturate quickly and thus $L_{d}$ will be decreased quickly. Because of the cross saturation effect the $L_{q}$ decrease with the increases of $I_{d}$. As some part of the q-axis magnetic circuit is the air, and the magnetic resistance of the air is very high, thus the q-axis inductance will not change greatly with the current increases. As shown, the $L_{d}$ in NSynRM is higher than that in TSynRM and the $L_{q}$ in NSynRM is lower than that in NSynRM, which is resulted by the adoption of grain oriented silicon steels.

Fig. 15 shows the torque waveform and the torque with the variation of current density and current of these two SynRMs. In Fig. 15, CD and NCD means the current density for the TSynRM and NSynRM respectively, and the unit is $\mathrm{A} / \mathrm{mm}^{2}$. It can be seen that for achieving maximum torque there is a determined current angle for the different current density. In SynRM, the optimal current angle is between 50 deg and 55 deg. As shown, NSynRM has higher torque ability especially when the current density is high. When current density is $16 \mathrm{~A} / \mathrm{mm}^{2}$ the torque for TSynRM and NSynRM is $185.5 \mathrm{Nm}$, and $198.2 \mathrm{Nm}$ respectively, and the torque increase rate is about $6.8 \%$. When the current density is $24 \mathrm{~A} / \mathrm{mm}^{2}$ the torque for TSynRM and NSynRM is $243.1 \mathrm{Nm}, 262.6 \mathrm{Nm}$ respectively and the torque increase rate is about $8 \%$. The torque increase rate $\left(T_{k}\right)$ defined as,

$$
T_{k}=\frac{T_{n}-T_{t}}{T_{t}} \times 100 \%
$$

where $T_{n}, T_{t}$ is the average torque of the NSynRM and TSynRM respectively. 
Figure 16 shows the power factor variation with the torque increases for these two machine. As the power factor is proportional to the saliency ratio, when the torque is low then the magnetic circuit along both the d-axis and qaxis is not saturated thus the power factor is high, however when the torque is high then the magnetic circuit will be saturated, then the power factor will be reduced. Compared with the TSynRM, the adoption of grain oriented silicon steels in the NSynRM releases the saturation problem, therefore its power factor is higher.

Fig. 17 shows the efficiency map of TSynRM and NSynRM. In Fig. 17 the imaginary line means the operation line under the rated current density of $16 \mathrm{~A} / \mathrm{mm}^{2}$. The rate speed is $4000 \mathrm{rpm}$, and torque decreases after the speed is over than $4000 \mathrm{rpm}$ since for keeping the voltage not higher than the rated voltage the current needs to be reduced or the current angle needs to be increased. It can be seen that the main efficiency of these two machines are quite similar and the efficiency has reached to $87 \%$ in the constant torque region and for the constant power region the efficiency has reached to about $95 \%$. As shown, the constant torque operation region of the NSynRM machine is about $17.5 \%$ wider than that of the NSynRM.

\section{Stress analysis}

As the grain oriented silicon steel sheets have replaced some part of the non oriented silicon steel sheets in the NSynRM, thus the effective magnetic bridge width has been reduced from $5.5 \mathrm{~mm}$ to $4 \mathrm{~mm}$ and thus the mechanical stress has been increased. In this paper, the mechanical stress of two SynRMs are analyzed at the maximum speed of $6000 \mathrm{rpm}$. Fig. 18 shows the stress distribution of these two SynRMs effected by both electromagnetic force and centrifugal force. As shown, the stress distribution are basically the same, and the maximum stress is appeared on the magnetic separation bridge. For NSynRM the maximum stress is higher and it is about $157 \mathrm{Mpa}$, and the maximum allowable tensile strength of the silicon steel sheet is about $305 \mathrm{MPa}$, which is still 2 times higher than the value of $157 \mathrm{Mpa}$. Therefore the NSynRM can still maintain the high mechanical strength when it operated at the maximum speed of $6000 \mathrm{rpm}$.

\section{Conclusion}

Based on the unique properties of grain oriented silicon steel sheets, a NSynRM is proposed in this paper. By using the FEM, the NSynRM and the benchmark TSynRM are both designed, optimized, analyzed and compared, some conclusions are obtained:

1) The magnetic barrier angle has a great influence on the torque ripple but low influence on the average torque; and the magnetic barrier thickness has a great influence on both the average torque and torque ripple. 
2) The saturation of magnetic bridge can be released by adding the grain-oriented silicon steels in the magnetic barrier with the rolling direction along the d-axis direction and the stacking direction along the q-axis direction.

3) The maximum torque has been improved about $8 \%$, the torque ripple has been reduced and the constant torque operation region has been improved about $17.5 \%$ in the NSynRM, as the adopted grain oriented silicon steel has very good electromagnetic performance in the rolling direction.

4) For stress analysis at the maximum speed, these two SynRMs have the similar stress distribution and the maximum stress is appeared at the magnetic separation bridge, and both of them can be operated at the maximum speed.

\section{Acknowledgements}

This work was supported in part by the Natural Science Foundation of Hebei Province under Project E2019202220, in part by National Natural Science Foundation of China under Project 51877065, in part by Hebei Province Education Department Youth Talent Leading Project under grant BJ2018037, and in part by the State Key Laboratory of Reliability and Intelligence of Electrical Equipment under Grant EERIKF2018005..

\section{Reference}

[1] J. T. Li, Z. J. Liu, M. A. Jabbar and X. K. Gao, Design optimization for cogging torque minimization using response surface methodology, IEEE Transactions on Magnetics 40(2) (2004), 1176-1179, doi: 10.1109/TMAG.2004.824809.

[2] A. Ikariga, H. Shimoji and T.Todaka, High-density permanent magnet machines, International Journal of Applied Electromagnetic and Mechanics 25(1-4) (2007), 19-23, doi: 10.3233/JAE-2007-836.

[3] W. Zhao and B. I. Kwon, Cost-effective permanent magnet shape for reducing cogging torque and torque ripple in surface-mounted permanent magnet machines, International Journal of Applied Electromagnetic and Mechanics 52(12) (2016), 817-825, doi: 10.3233/JAE-162119 .

[4] S. Tingna. Z. Yangshengmei and G. Liyan, Optimal Design of Rotor Geometry in Interior Permanent Magnet Machine. International Journal of Applied Electromagnetic and Mechanics 60(3) (2019).,337-353, doi: 10.3233/JAE-180090.

[5] K.Y. Hyun and L. J. Ho, Calculation on proportion of rotor shape for torque ripple reduction of axially laminated type synchronous reluctance motor. International Journal of Applied Electromagnetic and Mechanics 56(S1) (2018),153-162, 
doi: 10.3233/JAE-172292.

[6] S. Čorović, D. Zupančič, and D. Miljavec, Smoothing the static torque characteristic of synchronous reluctance motor by taguchi optimization method. International Journal of Applied Electromagnetic and Mechanics 56(2) (2018), 329345, doi: 10.3233/JAE-170106.

[7] J. H. Lee, Efficiency evaluations of synchronous reluctance motor using coupled FEM and preisach modeling, IEEE Transaction on Magnetics 39(5) (2003),3271-3273, doi: 10.1109/TMAG.2003.816745.

[8] J. Kolehmainen, Synchronous reluctance motor with form blocked rotor, IEEE Transactions on Energy Conversion, 25(2) (2010),450-456, doi: 10.1109/TEC.2009.2038579.

[9] P. Alotto, M. Barcaro, N. Bianchi and M. Guarnieri, Optimization of interior PM motors with machaon rotor flux barriers, IEEE Transactions on Magnetics 47(5) (2011), 958-961, doi: 10.1109/TMAG.2010.2073450.

[10] S. Taghavi and P. Pillay, A novel grain-oriented lamination rotor core assembly for a synchronous reluctance traction motor with a reduced torque ripple algorithm, IEEE Transactions on Industry Applications 52(5) (2016), 3729-3738, doi: 10.1109/TIA.2016.2558162.

[11] J. Ma et al., Optimal design of an axial-flux switched reluctance motor with grain-oriented electrical steel, IEEE Transactions on Industry Applications 53(6) (2017), 5327-5337, doi: 10.1109/TIA.2017.2727438.

[12] R. E. Betz and M. G. Jovanovic, The brushless doubly fed reluctance machine and the synchronous reluctance machinea comparison, IEEE Transactions on Industry Applications 36(4) (2000), 1103-1110, doi: 10.1109/28.855966.

[13] G. J. Li, K. Zhang, Z. Q. Zhu and G. W. Jewell, Comparative studies of torque performance improvement for different doubly salient synchronous reluctance machines by current harmonic injection, IEEE Transactions on Energy Conversion 34(2) (2019), 1094-1104, doi: 10.1109/TEC.2018.2870753.

[14] R. Morales-Caporal and M. Pacas, A predictive torque control for the synchronous reluctance machine taking into account the magnetic cross saturation, IEEE Transactions on Industrial Electronics 54(2) (2007), 1161-1167, doi: 10.1109/TIE.2007.891783.

[15] S. D. Chu and S. Torii, Torque-speed characteristics of superconducting synchronous reluctance motors with DyBCO bulk in the rotor, IEEE Transactions on Applied Superconductivity 15(2) (2005), 2178-2181, doi: 10.1109/TASC.2005.849606.

[16] Y. Wang, D. Ionel, D. G. Dorrell and S. Stretz, Establishing the power factor limitations for synchronous reluctance machines, IEEE Transactions on Magnetics 51(11) (2015), 1-4, doi: 10.1109/TMAG.2015.2443713.

[17] N. Bianchi, S. Bolognani, D. Bon and M. Dai PrÉ, Torque harmonic compensation in a synchronous reluctance motor, IEEE Transactions on Energy Conversion 23(2) (2008), 466-473, doi: 10.1109/TEC.2007.914357. 
[18] R. Moghaddam and F. Gyllensten, Novel high-performance SynRM design method: An easy approach for a complicated rotor topology, IEEE Transactions on Industrial Electronics 61(9) (2014), 5058-5065, doi: 10.1109/TIE.2013.2271601.

[19] X.D. Sun, Z. Shi, G. Lei, Y.G. Guo, and J.G. Zhu. Analysis and design optimization of a permanent magnet synchronous motor for a campus patrol electric vehicle. IEEE Transactions on Vehicular Technology, 2019, 68(11): 10535-10544.

[20] X.D. Sun, Y.C. Shen, S.H. Wang, G. Lei, Z.B. Yang, and S.Y. Han. Core losses analysis of a novel 16/10 segmented rotor switched reluctance BSG motor for $\mathrm{HEVs} \mathrm{using} \mathrm{nonlinear} \mathrm{lumped} \mathrm{parameter} \mathrm{equivalent} \mathrm{circuit} \mathrm{model.} \mathrm{IEEE/ASME}$ Transactions on Mechatronics, 2018, 23(2): 747-757. 
Tab.1

Main parameters of TSynRM and NSynRM

\begin{tabular}{|c|c|c|c|}
\hline Parameters & TSynRM & NSynRM & Unit \\
\hline Peak voltage & 450 & 450 & $\mathrm{~V}$ \\
\hline Rated speed & 4000 & 4000 & rpm \\
\hline Max speed/ & 6000 & 6000 & rpm \\
\hline Air gap & 1 & 1 & $\mathrm{~mm}$ \\
\hline Stator outer diameter & 270 & 270 & $\mathrm{~mm}$ \\
\hline Rotor outer diameter & 140 & 140 & $\mathrm{~mm}$ \\
\hline Stack length & 83.82 & 83.82 & $\mathrm{~mm}$ \\
\hline Rated current density & 16 & 16 & $\mathrm{~A} / \mathrm{mm}^{2}$ \\
\hline Max current density & 24 & 24 & $\mathrm{~A} / \mathrm{mm}^{2}$ \\
\hline \multicolumn{2}{|c|}{ Young is modulus of silicon steel } & $1.95 \times 10^{5}$ & $\mathrm{MPa}$ \\
\hline \multicolumn{2}{|c|}{ Poisson ratio of silicon steel } & 0.26 & - \\
\hline \multicolumn{2}{|c|}{ Tensile strength of silicon steel } & 305 & $\mathrm{MPa}$ \\
\hline
\end{tabular}


Tab.2

Optimized parameters of TSynRM and NSynRM

\begin{tabular}{|c|c|c|c|c|}
\hline \multicolumn{2}{|c|}{ Parameters } & TSynRM & NSynRM & Unit \\
\hline \multirow{3}{*}{$\begin{array}{c}\text { Magnetic } \\
\text { barrier angle }\end{array}$} & $\beta_{1}$ & 4 & 2.5 & deg \\
\hline & $\beta_{2}$ & 6 & 3.5 & deg \\
\hline & $\beta_{3}$ & 2.5 & 2.5 & deg \\
\hline \multirow{3}{*}{$\begin{array}{c}\text { Flux-barrier } \\
\text { length }\end{array}$} & $W_{q 1}$ & 8 & 4.5 & $\mathrm{~mm}$ \\
\hline & $W_{q 2}$ & 8 & 6.5 & $\mathrm{~mm}$ \\
\hline & $W_{q 3}$ & 10 & 15 & $\mathrm{~mm}$ \\
\hline \multirow[t]{4}{*}{ Magnetic bridge } & $S_{q 2}$ & 5.5 & 4 & $\mathrm{~mm}$ \\
\hline & $S_{q 3}$ & 5.5 & 4 & $\mathrm{~mm}$ \\
\hline & $L_{q l}$ & - & 1.6 & $\mathrm{~mm}$ \\
\hline & $L_{q 2}$ & - & 1.3 & $\mathrm{~mm}$ \\
\hline Magnetic rib & $H_{l}$ & 2 & 2 & $\mathrm{~mm}$ \\
\hline
\end{tabular}


Fig.1 Rotor structure of SynRM, (a) TSynRM, (b) and (c) NSynRM

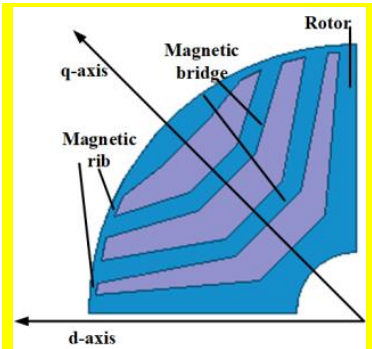

(a)

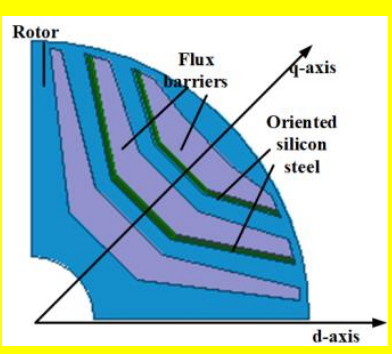

(b)

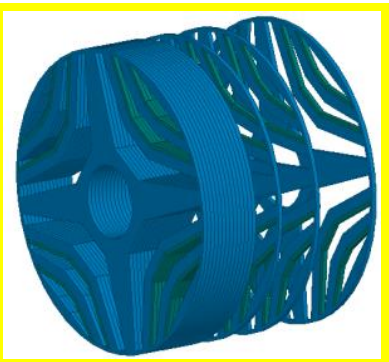

(c) 
Fig.2 Distribution diagram of magnetic flux lines of SynRM with d-axis current excitation

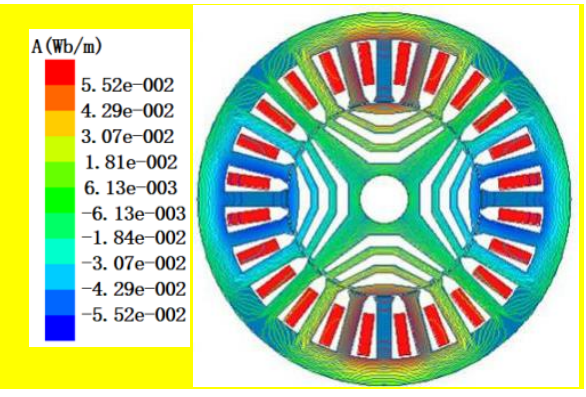


Fig.3 d-axis magnetic circuit model and d-axis equivalent magnetic circuit, (a) and (c) for TSynRM, (b) and (d) for NSynRM

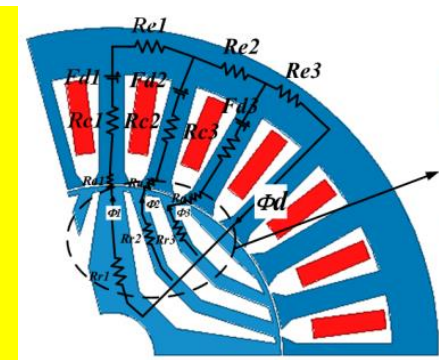

(a)

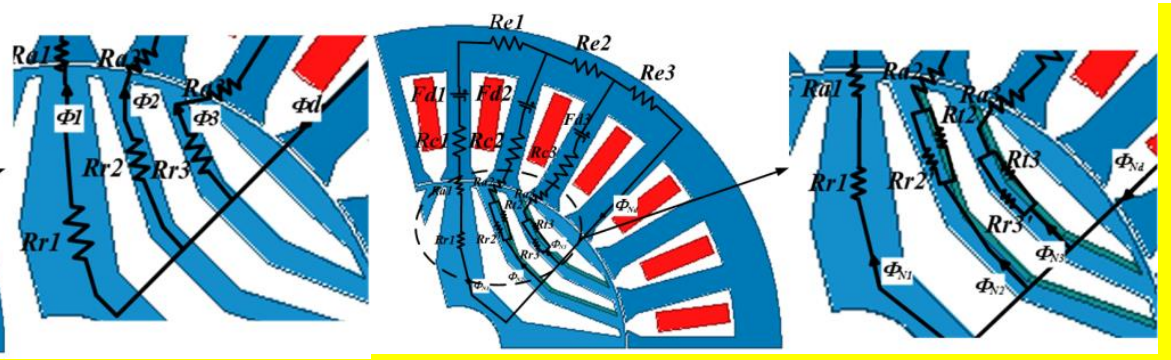

(b)

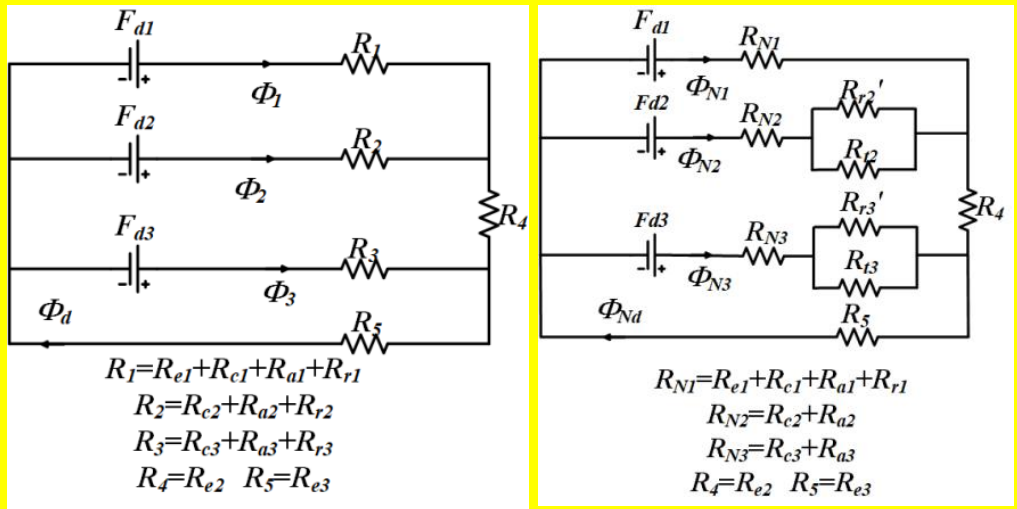

(c) 
Fig.4 Distribution diagram of magnetic flux lines of SynRM with q-axis excitation

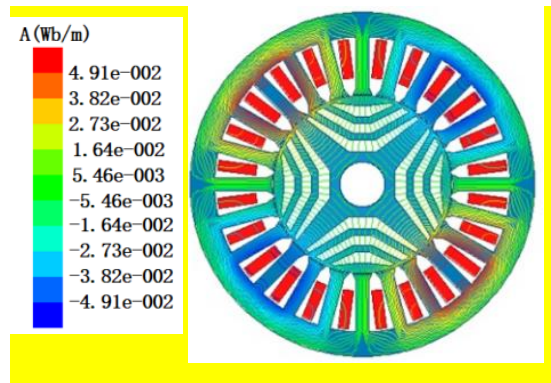


Fig.5 q-axis magnetic circuit model and q-axis equivalent magnetic circuit (a) and (c) for TSynRM, (b) and (d) for NSynRM

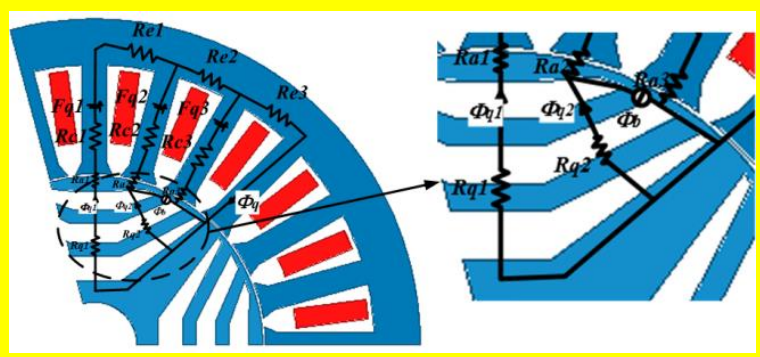

(a)

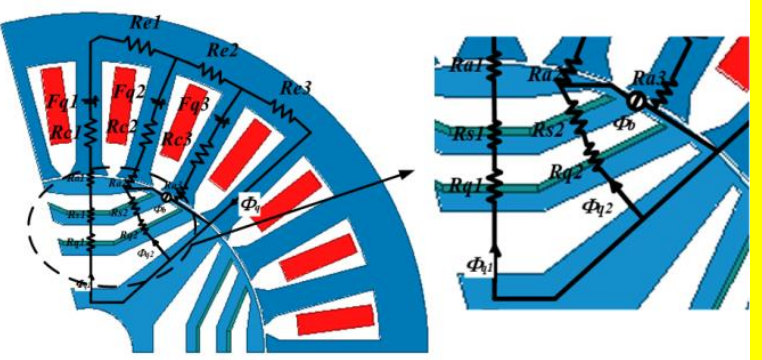

(b)

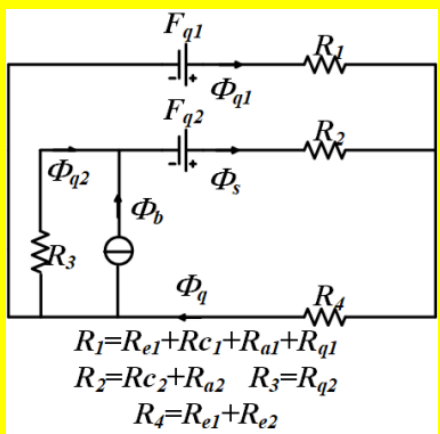

(c)

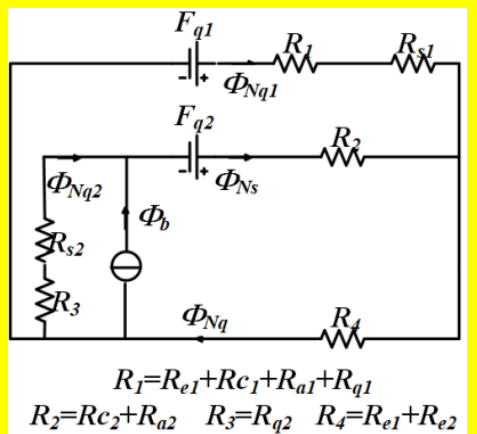

(d) 
Fig.6 Flux density map of rotor fed by $20 \mathrm{~A} / \mathrm{mm} 2$ current density, (a) B-H curve for non-grain oriented silicon steel, (b) B-H curve for grain oriented silicon steel along the stacking direction, (c) B-H curve for grain oriented silicon steel along the shear direction, (d) flux density distribution of TSynRM, and (e) flux density distribution of NSynRM

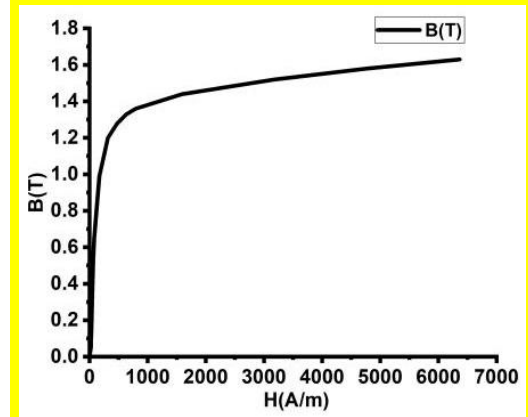

(a)

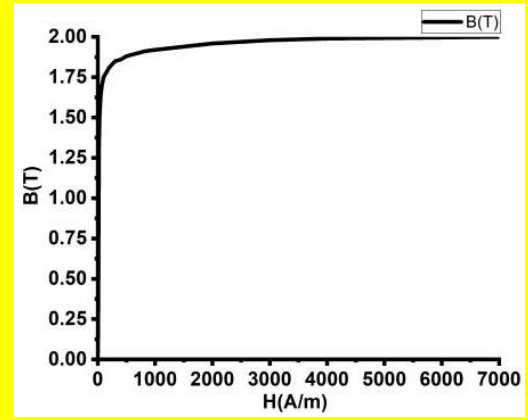

(b)

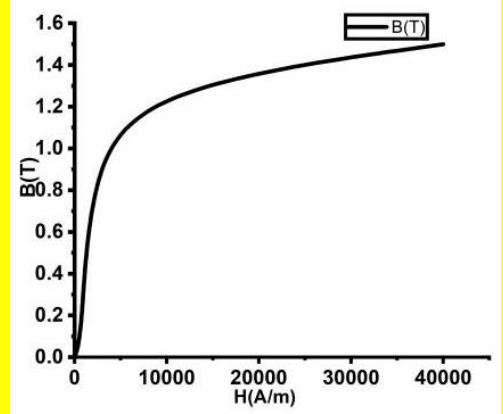

(c)

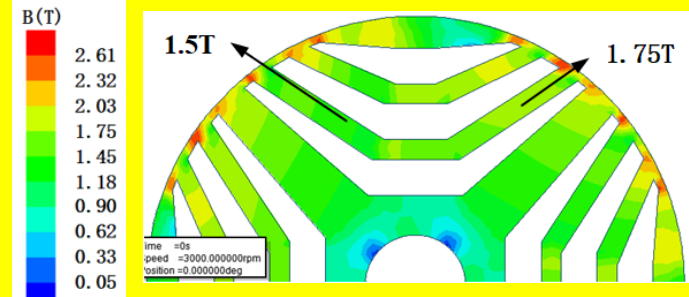

(d)

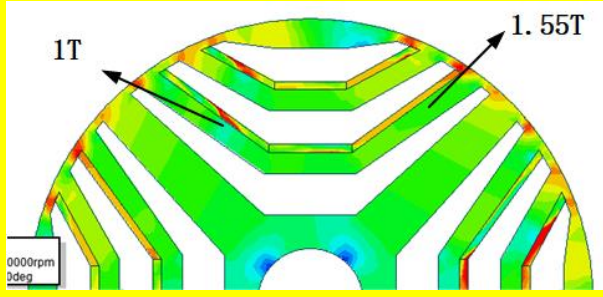

(e) 
Fig.7 Rotor structure of TSynRM

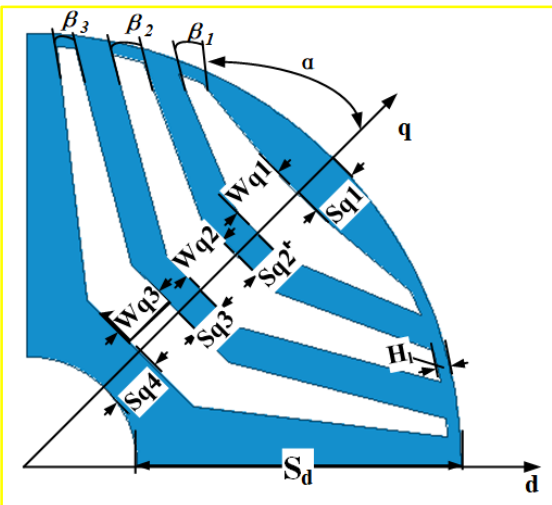


Fig.8 Torque characteristics of TSynRM with different flux barrier end angles,(a) (b)and(c) torque, (d) (e)and(f) torque ripple

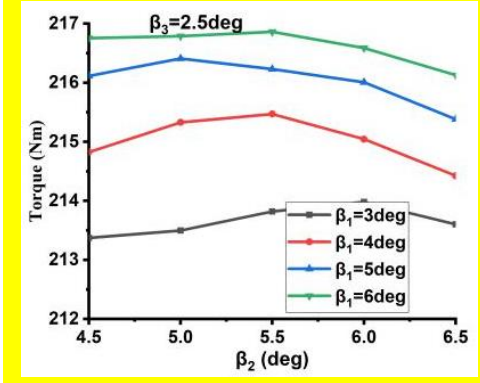

(a)

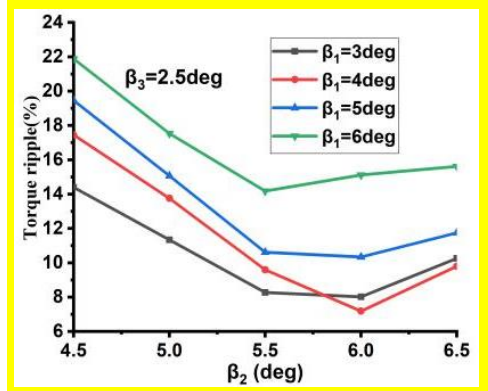

(d)

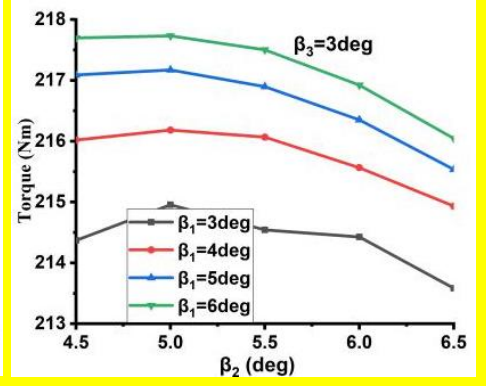

(b)

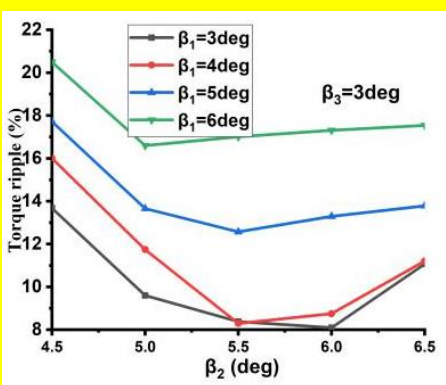

(e)

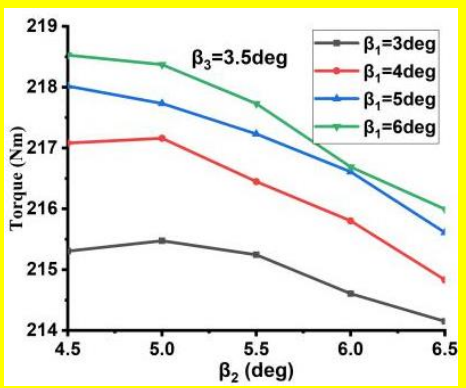

(c)

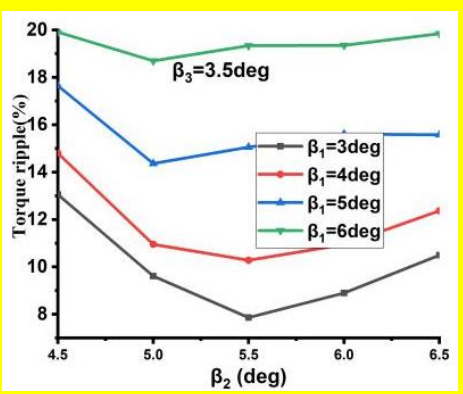

(f) 
Fig.9 Torque characteristics of TSynRM with different flux barrier width, (a) torque and (b) torque ripple

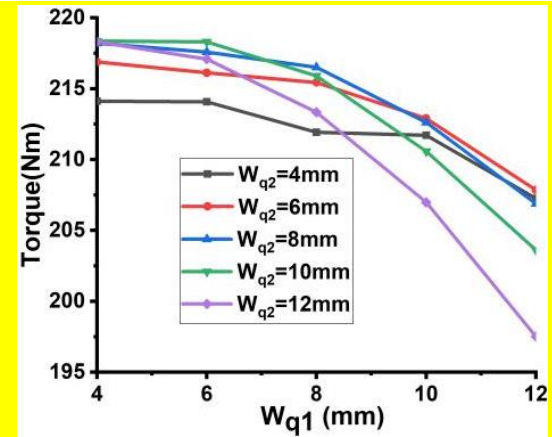

(a)

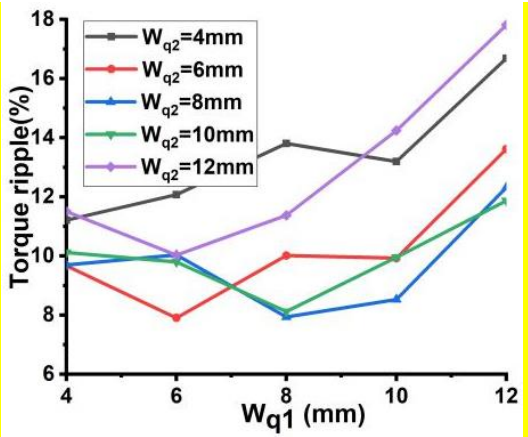

(b) 
Fig.10 Rotor structure of NSynRM

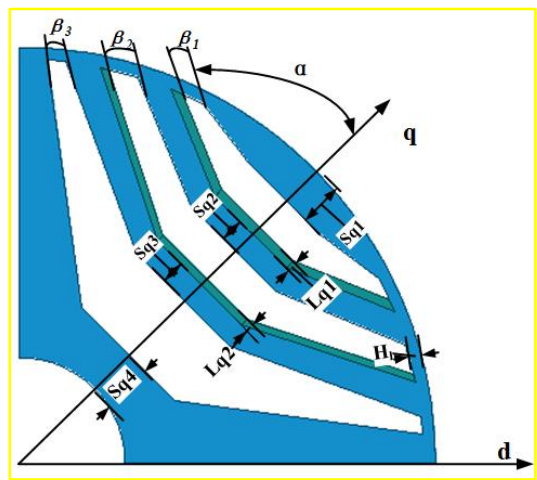


Fig.11 Torque characteristics of NSynRM with different flux barrier end angle, (a) (b)and(c) torque, (d) (e)and(f) torque ripple

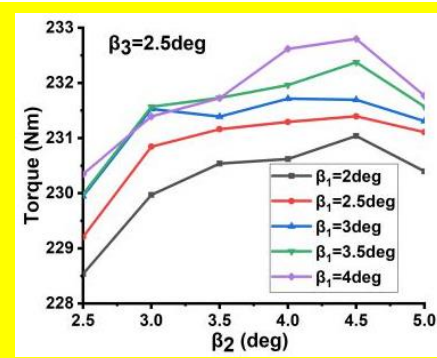

(a)

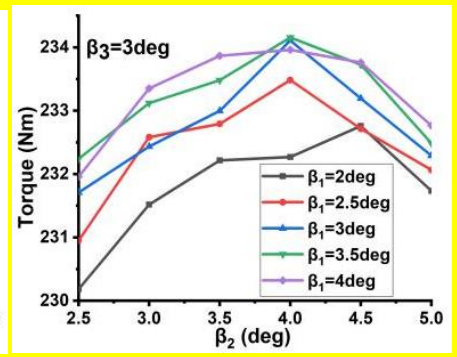

(b)

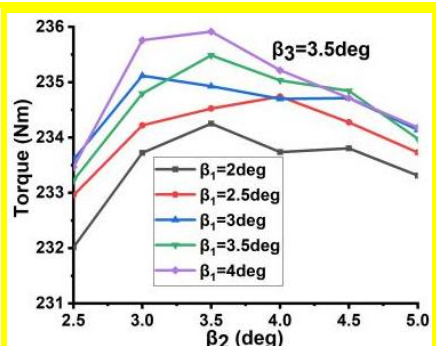

(c)

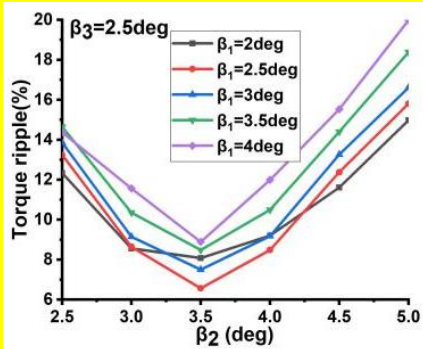

(d)

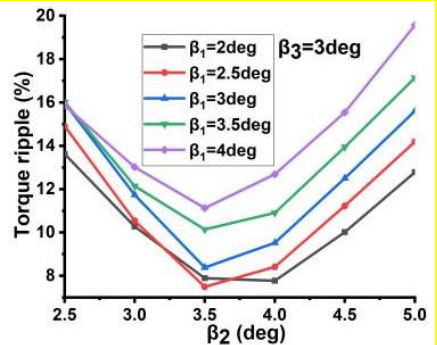

(e)

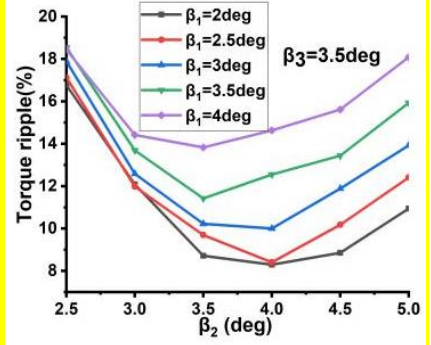

(f) 
Fig. 12 Torque characteristics of NSynRM with different flux barrier width, (a) average torque and (b) torque ripple

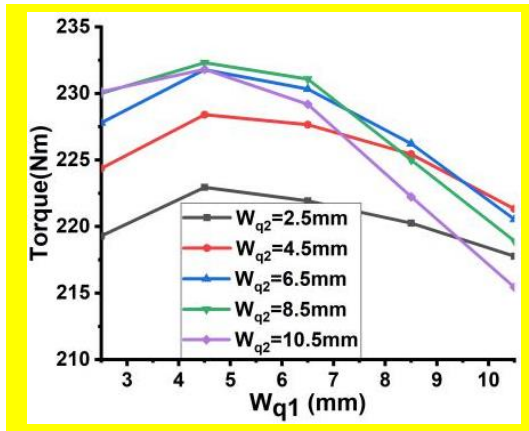

(a)

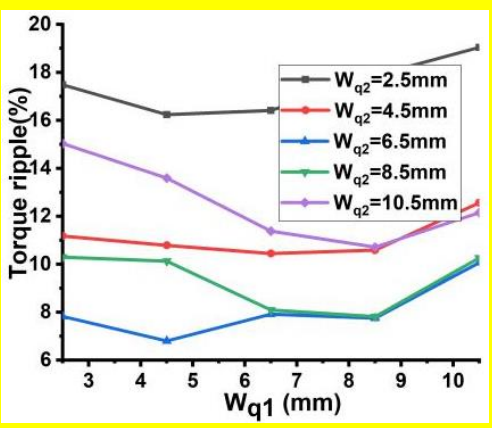

(b) 
Fig.13 Torque characteristics of NSynRM with different oriented electrical steel width, (a) average torque and (b) torque ripple

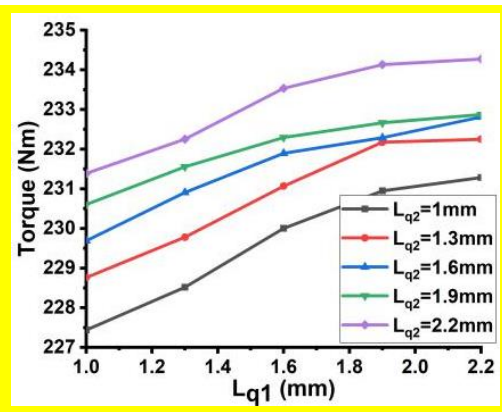

(a)

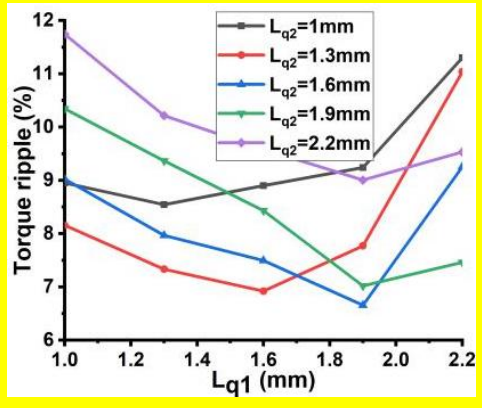

(b) 
Fig.14 Inductance versus current diagram, (a) Ld for TSynRM, (b) Lq for TSynRM, (c) Ld for NSynRM, and (d) Lq for NSynRM

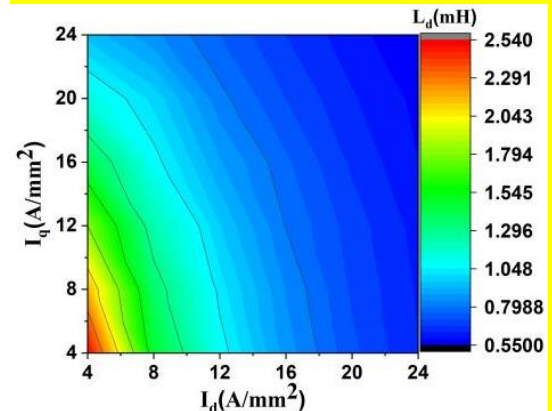

(a)

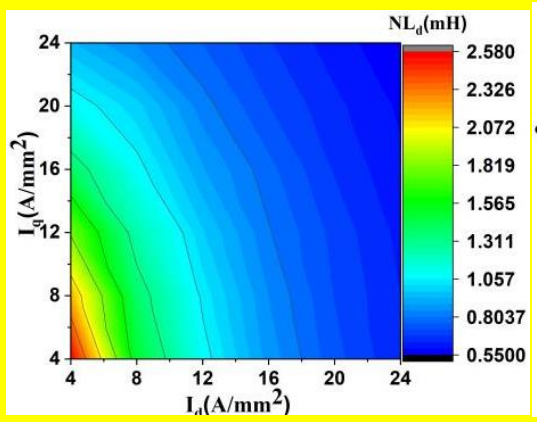

(c)

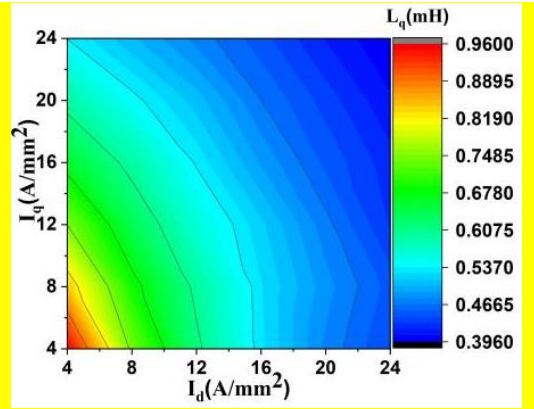

(b)

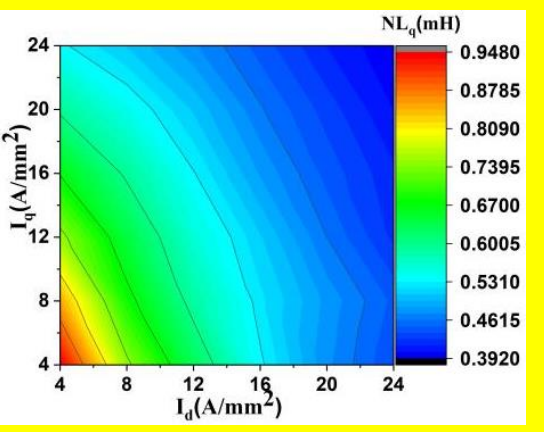

(d) 
Fig.15 Torque versus current, (a) torque waveform, (b) torque versus current and current angle

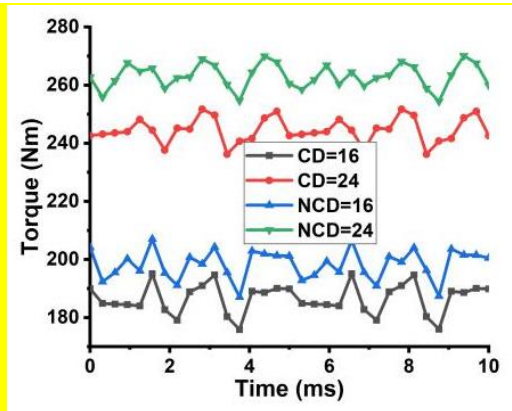

(a)

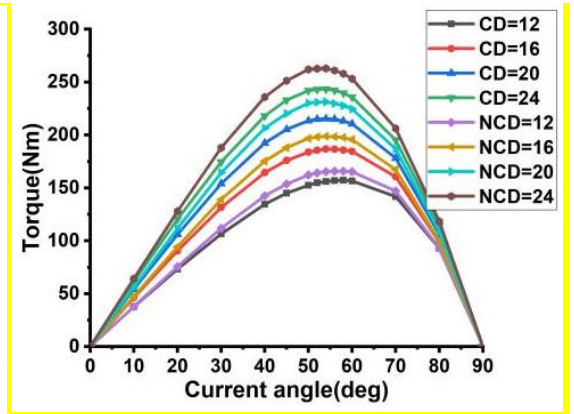

(b) 
Fig.16 Power factor versus torque curve

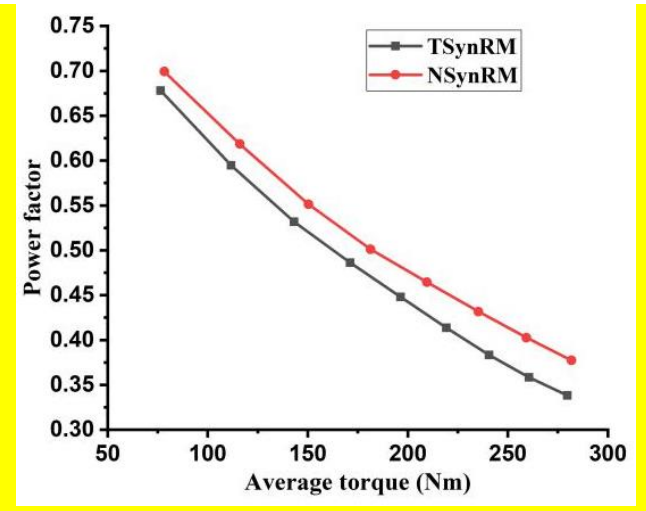


Fig.17 Efficiency map of (a) TSynRM and (b) NSynRM

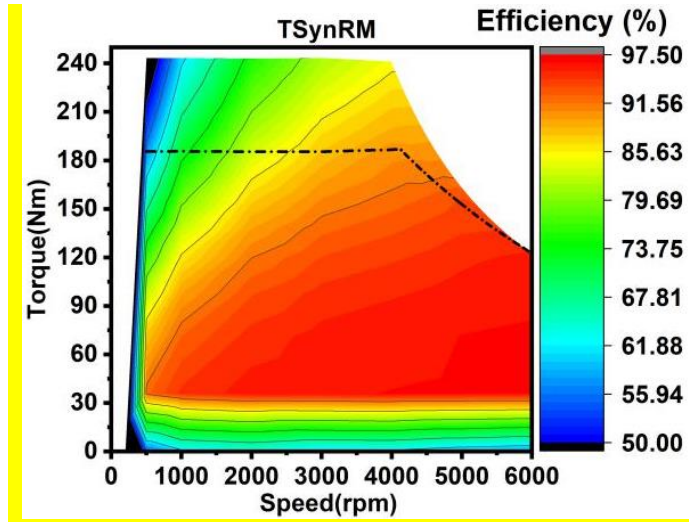

(a)

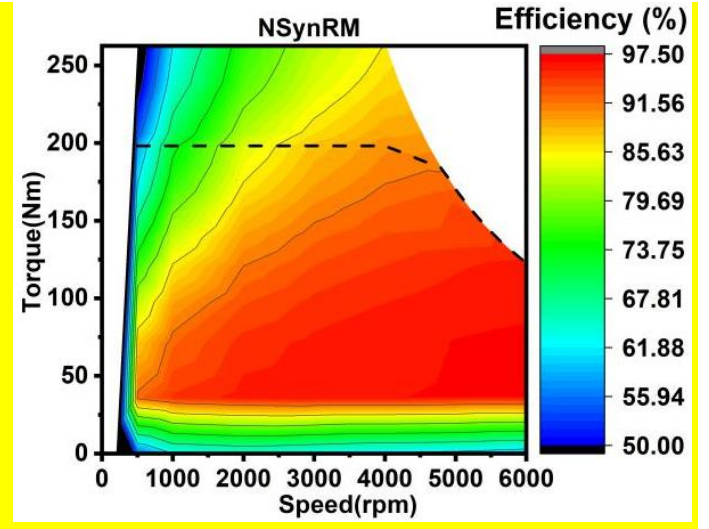

(b) 
Fig.18 Equivalent stress analysis. (a)NSynRM. (b)TSynRM.

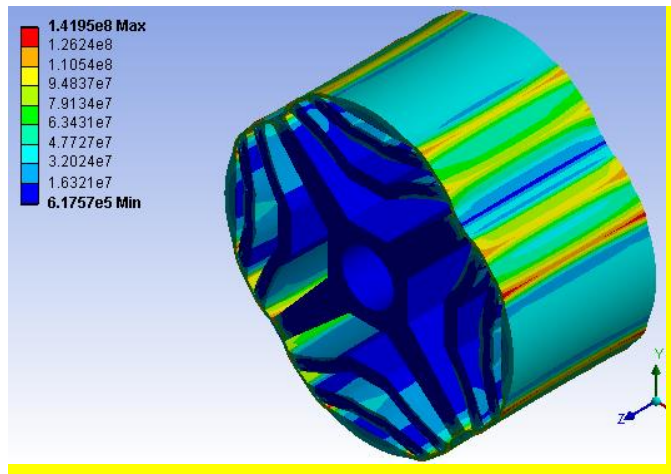

(a)

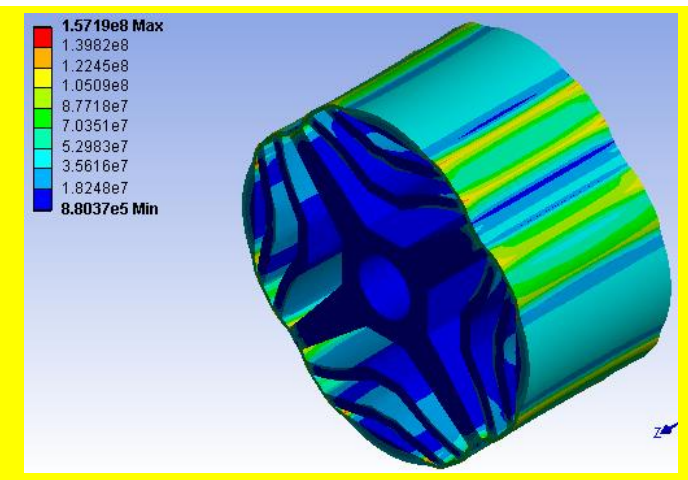

(b) 